\section{Riddle of the tenth man}

SIR - While describing the history of the revelation of the Piltdown hoax, Henry $\mathrm{Gee}^{1}$ says that the "chemical analyses by Kenneth P. Oakley of the museum [British Museum (Natural History)] showed that all the artefacts were of recent date". Because the artefacts were of extreme importance and were registered at the museum, it was decreed that they could not be removed from the museum precincts and that no samples could be taken for analysis either within or outside the museum.

The Machiavellian minds of the lawyers, however, decided that it could be considered that the objects could be deemed to be still in the museum if they were in the charge of the curator and if they were returned before nightfall. I had recently developed X-ray fluorescence analysis (XRF) as a nondestructive method of chemical analysis, which was also very rapid and ideally suited if the surface was to be investigated. Indeed, these analyses were probably the very first practical use of XRF for either academic or commercial purpos$\mathrm{es}^{2,3}$. (Many other methods of chemical and physical examination using classical techniques were used by the Natural History Museum after it had been discovered ${ }^{4}$ that the bones were not in fact so irreplaceable!)

When mentioning the comparison of the staining on the original Piltdown specimens and the teeth found in Hinton's trunk, Gee quotes Professor Brian Gardiner as accusing Martin Hinton (late of the Natural History Museum) of the fraud, and saying: "But Oakley did not look for manganese. Crucially, analyses of the contents of Hinton's trunk by Currant and Gardiner show that they are enriched in iron as well as manganese - in the same proportions as in the Piltdown specimen." To quote from my thesis": “... all specimens were also analysed for manganese which was found to be absent in all cases down to the sensitivity limits of the apparatus. Potassium permanganate staining had been suspected but it was shown that no such treatment had taken place." It is clear, therefore, that if manganese has been found in the recently discovered "trunk" samples, it is evidence that the two sources are not similar.

Gee's report gives a description of how the staining of the bones was achieved by treatment with chromic acid in order to turn the bone apatite to gypsum. It is not clear to me why apatite (calcium phosphate) should be turned into gypsum (calcium sulphate) by treatment with chromic acid. Moreover, during the work carried out in 1953, it was evident that the chromium was associated with potassium ions, and there is little doubt that it was potassium dichromate that was used in the staining process and not chromic acid. Indeed, experiments were carried out to test this hypothesis using other bone samples; the results gave final products very similar to the original in both chemical analysis and colours. Incidentally, Gardiner claims that the orang-utan mandible was not stained in the same way as the other artefacts, whereas reference to the 1953 thesis shows that its chromium content is very close to the average chromium content of the other eight chromiumstained samples.

I have a list of nine other candidates who have been cited at one time or another as the Piltdown forger. Martin Hinton, whom Gardiner now believes was the perpetrator, is just another to be added to this list. The evidence presented may show that he was involved, probably with others, but in no way is it proved. Charles Dawson, a proven fraudster in other spheres, seems a much more likely candidate.

\section{E. T. Hall}

Research Laboratory for Archaeology and the History of Art,

University of Oxford,

6 Keble Road,

Oxford OX1 3QJ, UK

1. Nature 381, 262-262 (1996).

2. Hall, E. T. thesis, Oxford Univ. (1953).

3. Weiner, J. S., Oakley, K. P. \& Le Gros Clark, W. E. Bull. Brit. Mus. (Nat. Hist.) Geol. Series 2, No. 3 (1953) 4. Bull. Brit. Mus. (Nat. Hist.) Geol. Series 2, No. 6 (1955).

SIR - Brian Gardiner's contention that Martin A. C. Hinton was the perpetrator of the Piltdown hoax adds another culprit, but he lets Charles Dawson off the hook too easily. He should also consider the chapter on "The Piltdown Perpetrator" in the book Mysterious Realms by Joe Nickell with John F. Fischer (Prometheus Books, Amherst, New York, 1992).

Dawson was the one person consistently present at all the Piltdown discoveries. To say he was Hinton's dupe throughout gives Hinton almost omniscient power over Dawson. It is far more likely, given the discovery of Hinton's trunk of coloured bones at the museum, that Hinton was a collaborator, even the junior partner in the affair. For the discoveries at Piltdown ceased with Dawson's death. If Hinton was the real mastermind, he would have found some other dupe, and the discoveries at Piltdown would have continued.

Dawson also tried to pass off other frauds - a plagiarized book as his own, crytozoological creatures and bogus artefacts. Dawson consistently appears as the most likely perpetrator of the Piltdown hoax. What Gardiner has done is to discover Dawson's accomplice.

\section{Andrew 0. Lutes}

658 Mansfield-Lucas Road,

Mansfield,

Ohio 44907-1814, USA

\section{Energy, not bombs}

SIR - It is unfortunate that Nature (381, 267 ; 1996) has joined in the criticism of India's approach to a Comprehensive Test Ban Treaty (CTBT).

In contrast to that of its neighbour, China, the primary focus of India's nuclear programme has been to provide energy for its people. As a result, India's nuclear energy programme is the second largest indigenous programme in Asia, after that of Japan. Furthermore, India's capability since 1960 to manufacture nuclear weapons is well documented $(\mathrm{K}$. D. Nichols, The Road to Trinity 351-352, William Morrow, New York, 1987). India was one of the few countries with this capability (although it faced consistent threats on its borders) to have shown restraint. It was only after the emergence of the alliance between the United States and China in 1973, however, that India felt threatened and demonstrated its capability with a sophisticated nuclear explosion test in 1974. Since then, India has not tested any other device.

Rather than criticizing India, therefore, the declared nuclear powers should set an example and move towards total nuclear disarmament within a realistic time-frame. This would give the CTBT universal appeal. In fact, the late Rajiv Gandhi suggested a time-frame for the total liquidation of weapons of mass destruction. Quite recently, Pope John Paul II expressed similar views.

\section{Upindar Fotadar}

Department of Microbiology and

Molecular Genetics, Room 1.768,

Freeman Building,

University of Texas Medical Center,

6431 Fannin,

Houston, Texas 77030 , USA

\section{History lesson}

SIR - I refuse to accept Henry I. Miller's comparison of the Nazis with groups in Germany opposed to field tests (Nature 381, 362; 1996). I also reject the term "Entartete Forschung". I do not agree with the activities of groups in Germany opposed to genetic engineering, but to equate them with the criminals of Nazi Germany is just stupid.

During my two-year stay in the United States I met too many people who may have learned a lot, even history, but have understood nothing. Miller's letter is another example.

\section{Karl Friehs}

Institute for Fermentation Technology,

University Bielefeld,

Technische Fakultät,

PO Box 100131

D-33501 Bielefeld, Germany

e-mail: kfr@fermtech.techfax.uni-bielefeld.de 